\title{
Independent Impact of Diabetes on the Severity of Coronavirus Disease 2019 in 5,307 Patients in South Korea: A Nationwide-Cohort Study (Diabetes Metab J 2020;44:737-46)
}

\author{
Kyuho Kim ${ }^{1}$, Tae Jung $\mathrm{Oh}^{1,2}$ \\ ${ }^{1}$ Department of Internal Medicine, Seoul National University Bundang Hospital, Seongnam, \\ ${ }^{2}$ Department of Internal Medicine, Seoul National University College of Medicine, Seoul, Korea
}

Accelerated spread of coronavirus disease 2019 (COVID-19) has led to the COVID-19 pandemic. Previous studies reported that old age [1], diabetes [2], obesity [3], chronic cardiac disease, and chronic pulmonary disease [4] are associated with poor prognosis of COVID-19. Many of these studies were based on data from hospitalized patients. Therefore, whether these findings are consistent in unhospitalized patients remains unclear, especially in South Korea.

In this article entitled, "Independent impact of diabetes on the severity of coronavirus disease 2019 in 5,307 patients in South Korea: a nationwide-cohort study," Moon et al. [5] aimed to elucidate the association between diabetes and clinical outcomes of COVID-19 using nationwide claims data regardless of hospitalization. That was the main strength of the study, which included the entire national population when assessing the association between diabetes and worse clinical outcomes regardless of hospitalization. Among 5,307 patients, COVID-19 patients with diabetes had a higher rate of severe outcomes, including oxygen treatment, ventilator use, and mortality, than those without diabetes. Even after adjustment for other risk factors, the risk of severe outcomes was higher in patients with diabetes than in those without diabetes. These findings are in line with recent studies [6,7].

However, there are several issues to be discussed with regard to this study. First, the definition of diabetes was based on a prescription for antidiabetic drugs in the one year before diagnosis of COVID-19. Considering that $37.4 \%$ of patients with diabetes were undiagnosed and $43.1 \%$ of diabetes in South Korea did not receive treatment [8], the criteria used in this study may have underestimated diabetes, which is not negligible. Furthermore, Li et al. [9] recently showed that newly diagnosed diabetes was related to a higher risk of mortality compared to established diabetes. Secondly, the severity of diabetes such as the level of glycosylated hemoglobin, diabetes duration, and insulin use were not addressed. At least insulin use could be captured from medical claims data. Considering that poorly controlled blood glucose is associated with higher mortality in patients with COVID-19 and type 2 diabetes mellitus [6], it would be useful to consider the severity of diabetes. In addition, the presence of obesity, based on either diagnostic code or body mass index, was not addressed. Obesity is an independent risk factors for severe COVID-19 [3] and it is interrelated with diabetes. Lastly, outcome differences between regions were not addressed. By May 15, 2020, about $80 \%$ of COVID-19 patients were confirmed to reside in the DaeguGyeongbuk province, and therefore there were shortages of inpatient beds and other healthcare resources in this province [10]. Under the circumstances, if the authors analyzed the data
Corresponding author: Tae Jung Oh (iD https://orcid.org/0000-0002-5078-6123 Department of Internal Medicine, Seoul National University Bundang Hospital, Seoul National University College of Medicine, 82 Gumi-ro 173beon-gil, Bundang-gu, Seongnam 13620, Korea

E-mail: ohtjmd@gmail.com
This is an Open Access article distributed under the terms of the Creative Commons Attribution Non-Commercial License (https://creativecommons.org/licenses/by-nc/4.0/) which permits unrestricted non-commercial use, distribution, and reproduction in any medium, provided the original work is properly cited. 
according to the location, we could further explore the influence of scarce healthcare resources on outcomes.

In conclusion, this nationwide population-based cohort study demonstrated that diabetes was associated with worse clinical outcomes in patients with COVID-19. This finding provides important insights into the prevention and treatment of COVID-19 in patients with diabetes. However, further analysis including key parameters such as the severity of diabetes and obesity is necessary for a better understanding.

\section{CONFLICTS OF INTEREST}

No potential conflict of interest relevant to this article was reported.

\section{REFERENCES}

1. Zhou F, Yu T, Du R, Fan G, Liu Y, Liu Z, Xiang J, Wang Y, Song B, Gu X, Guan L, Wei Y, Li H, Wu X, Xu J, Tu S, Zhang Y, Chen $\mathrm{H}, \mathrm{Cao}$ B. Clinical course and risk factors for mortality of adult inpatients with COVID-19 in Wuhan, China: a retrospective cohort study. Lancet 2020;395:1054-62.

2. Shi Q, Zhang X, Jiang F, Zhang X, Hu N, Bimu C, Feng J, Yan S, Guan Y, Xu D, He G, Chen C, Xiong X, Liu L, Li H, Tao J, Peng $\mathrm{Z}$, Wang W. Clinical characteristics and risk factors for mortality of COVID-19 patients with diabetes in Wuhan, China: a two-center, retrospective study. Diabetes Care 2020;43:138291.

3. Tamara A, Tahapary DL. Obesity as a predictor for a poor prognosis of COVID-19: a systematic review. Diabetes Metab Syndr 2020;14:655-9.

4. Cummings MJ, Baldwin MR, Abrams D, Jacobson SD, Meyer BJ, Balough EM, Aaron JG, Claassen J, Rabbani LE, Hastie J,
Hochman BR, Salazar-Schicchi J, Yip NH, Brodie D, O'Donnell MR. Epidemiology, clinical course, and outcomes of critically ill adults with COVID-19 in New York City: a prospective cohort study. Lancet 2020;395:1763-70.

5. Moon SJ, Rhee EJ, Jung JH, Han KD, Kim SR, Lee WY, Yoon $\mathrm{KH}$. Independent impact of diabetes on the severity of coronavirus disease 2019 in 5,307 patients in South Korea: a nationwide cohort study. Diabetes Metab J 2020;44:737-46.

6. Zhu L, She ZG, Cheng X, Qin JJ, Zhang XJ, Cai J, Lei F, Wang H, Xie J, Wang W, Li H, Zhang P, Song X, Chen X, Xiang M, Zhang C, Bai L, Xiang D, Chen MM, Liu Y, Yan Y, Liu M, Mao W, Zou J, Liu L, Chen G, Luo P, Xiao B, Zhang C, Zhang Z, Lu Z, Wang J, Lu H, Xia X, Wang D, Liao X, Peng G, Ye P, Yang J, Yuan Y, Huang X, Guo J, Zhang BH, Li H. Association of blood glucose control and outcomes in patients with COVID-19 and pre-existing type 2 diabetes. Cell Metab 2020;31:1068-77.e3.

7. Barron E, Bakhai C, Kar P, Weaver A, Bradley D, Ismail H, Knighton P, Holman N, Khunti K, Sattar N, Wareham NJ, Young B, Valabhji J. Associations of type 1 and type 2 diabetes with COVID-19-related mortality in England: a whole-population study. Lancet Diabetes Endocrinol 2020;8:813-22.

8. Kim BY, Won JC, Lee JH, Kim HS, Park JH, Ha KH, Won KC, Kim DJ, Park KS. Diabetes fact sheets in Korea, 2018: an appraisal of current status. Diabetes Metab J 2019;43:487-94.

9. Li H, Tian S, Chen T, Cui Z, Shi N, Zhong X, Qiu K, Zhang J, Zeng T, Chen L, Zheng J. Newly diagnosed diabetes is associated with a higher risk of mortality than known diabetes in hospitalized patients with COVID-19. Diabetes Obes Metab 2020; 22:1897-906.

10. Kim JH, An JAR, Min P, Bitton A, Gawande AA. How South Korea responded to the Covid-19 outbreak in Daegu. NEJM Catal Innov Care Deliv 2020;1:1-14. 